\title{
Pengembangan Digital Signage sebagai Papan Informasi Digital Studi Kasus: STMIK AUB Surakarta
}

\author{
Ernes Cahyo Nugroho**1, Erni Widarti ${ }^{2}$, Neira Anjar Pujisusilo ${ }^{3}$, Bayu Adi Catur ${ }^{4}$ \\ 1,2,3,4Program Studi Sistem Komputer, STMIK AUB, Surakarta, Indonesia \\ e-mail: *1ernes.cahyo@stmik-aub.ac.id, ${ }^{2}$ erni.widarti@stmik-aub.ac.id, \\ 3neira.anjr@gmail.com, ${ }^{4}$ syifabayu5@gmail.com
}

\begin{abstract}
Abstrak
STMIK AUB Surakarta telah memanfaatkan media website sebagai sarana penyampaian informasi. Namun dalam lingkungan internal masih menggunakan cara konvensional dengan menempel lembar pengumuman pada papan informasi yang tersedia, masih banyak informasi atau pengumuman yang harus disampaikan dengan cepat, informatif dan up to date, seperti informasi proses belajar mengajar, agenda atau kegiatan di jurusan, maupun informasi lainnya yang berhubungan dengan layanan konvensional dan statis melalui papan pengumuman. Informasi yang diberikan menggunakan lembaran yang ditempelkan di papan informasi yang tersedia. Dengan cara ini tentu akan memboroskan kertas dan biaya, karena hanya digunakan sekali saja, setelah pengumuman itu kadaluarsa, lembaran informasi tersebut tidak berguna lagi dan dapat memberikan kesan kotor pada papan bekas tempelan selembaran kertas pengumuman tersebut. Tujuan dari penelitian ini adalah menyampaikan segala informasi tentang STMIK AUB Surakarta secara menarik, informatif, dinamis, dan real time. Peneliti memberikan solusi dengan menggunakan Digital Signage sebagai papan informasi digital yang dapat menyajikan informasi secara up to date, informatif, dinamis, dan menarik. Hasil dari penelitian ini adalah perangkat Digital Signage dengan menggunakan Android TV Box sebagai media pemutar konten yang berupa gambar, video, dan text, serta LCD TV sebagai tampilan layarnya. Untuk TV yang sudah Smart TV tidak memerlukan perangkat Android TV Box. Kesimpulan penelitian ini adalah Digital Signage dapat digunakan untuk menyampaikan informasi pada STMIK AUB Surakarta. Digital Signage dapat menyampaikan informasi secara up to date, informatif, dinamis, dan menarik. Digital Signage dapat menyampaikan informasi secara real time tanpa perlu menunggu dalam jangka waktu yang lama.
\end{abstract}

Kata kunci-Digital Signage, Content Management System (CMS), Informasi, STMIK AUB

\begin{abstract}
STMIK AUB Surakarta has used website media as a means of delivering information. However, in the internal environment, they still use conventional methods by sticking to the announcement sheet on the information boards available, there is still a lot of information or announcements that must be delivered quickly, informative and up to date, such as information on teaching and learning processes, agendas or activities in the department, as well as other information dealing with conventional and static services through bulletin boards. The information provided uses sheets that are posted on the information boards provided. In this way it would be a waste of paper and costs, because it is only used once, after the announcement has expired, the information sheet is no longer useful and can give a dirty impression on the old post board of the paper sheet. The purpose of this study is to convey all
\end{abstract}


information about STMIK AUB Surakarta in an interesting, informative, dynamic and real time manner. Researchers provide solutions by using Digital Signage as a digital information board that can present information up to date, informative, dynamic, and interesting. The results of this study are Digital Signage devices using Android TV Box as a media player in the form of image content, video, and text, and LCD TV as the screen display. Smart TVS do not require an Android TV Box device. The conclusion of this research is that Digital Signage can be used to convey information at STMIK AUB Surakarta. Digital Signage can convey information that is up to date, informative, dynamic, and interesting. Digital Signage can convey information in real time without the need to wait for a long period of time.

Keywords - Digital Signage, Content Management System (CMS), Information, STMIK AUB

\section{PENDAHULUAN}

Informasi saat ini menjadi kebutuhan yang mendasar bagi setiap individu maupun institusi. Persaingan yang mengacu kearah peningkatan pelayanan dan kepuasan pelanggan, mengharuskan para produsen atau intitusi memadukan teknologi digital kedalam sistem advertisement. Perkembangan teknologi memberikan berbagai macam kemudahan bagi para penggunanya. Digital signage dianggap memiliki peranan penting dalam memberikan layanan informasi. Dengan sistem yang hanya terdiri dari komposisi server atau PC, monitor atau TV dan software menjadikan digital signage ini lebih efisien dalam segi waktu, tenaga dan biaya $[2,8]$.

Di era digital, papan pengumuman bermigrasi dari bentuk konvensional ke bentuk digital, sehingga dikenal istilah digital signage. Bentuk digital signage yang sering diterapkan saat ini adalah menggunakan seperangkat komputer yang dihubungkan ke satu atau beberapa buah TV Plasma untuk menampilkan informasi. Salah satu perangkat keras digital signage yang mendukung proses pembuatan papan pengumuman digital berbasis Web adalah Set Top Box (STB) Android. Banyak kelebihan yang ditawarkan oleh digital signage sebagai media untuk menyebarkan informasi ke target penonton dari pada media konvensional. Digital signage bersifat dinamis, konten dapat diperbaharui kapanpun sesuai kebutuhan tanpa harus mengeluarkan biaya lagi untuk percetakan [1].

STMIK AUB Surakarta telah memanfaatkan media website sebagai sarana penyampaian informasi. Namun dalam lingkungan internal masih menggunakan cara konvensional dengan menempel lembar pengumuman pada papan informasi yang tersedia, masih banyak informasi atau pengumuman yang harus disampaikan dengan cepat, informatif dan up to date, seperti informasi proses belajar mengajar, agenda atau kegiatan di jurusan, maupun informasi lainnya yang berhubungan dengan layanan konvensional dan statis melalui papan pengumuman. Informasi yang diberikan menggunakan lembaran yang ditempelkan di papan informasi yang tersedia. Dengan cara ini tentu akan memboroskan kertas dan biaya, karena hanya digunakan sekali saja, setelah pengumuman itu kadaluarsa, lembaran informasi tersebut tidak berguna lagi dan dapat memberikan kesan kotor pada papan bekas tempelan selembaran kertas pengumuman tersebut. sehingga timbul beberapa permasalahan yaitu tidak semua calon mahasiswa baru dapat mengetahui informasi yang disampaikan, karena kertas yang ditempel sudah hilang. Informasi yang disampaikan tidak fleksibel dan tidak menarik. Sulit untuk diubah dalam waktu yang singkat serta tidak dapat didistribusikan secara real-time. Materi publikasi tidak bisa disesuikan dengan target audiens. Tidak ramah lingkungan karena masih menggunakan kertas.

Maka dari itu penulis melakukan penelitian dengan cara membuat papan pengumuman atau Digital Signage yang bertujuan untuk mengurangi permasalahan yang telah dipaparkan sebelumnya. Pada penelitian ini, proses pembuatan papan pengumuman digital dilakukan dengan cara membuat sebuah sistem yang terdiri dari komposisi software (Notepad++, MySQL, Web Hosting, dan Internet) dan hardware (STB Android, PC Server, PC Client dan LED TV). Aplikasi berbasis web menggunakan bahasa pemrograman PHP yang telah dibuat diinstallkan 
pada web hosting melalui PC Server, sedangkan LED TV dihubungkan dengan STB Android digunakan untuk menampilkan display aplikasi berbasis web pada papan pengumuman digital yang telah dibuat agar terlihat lebih tajam, cerah, dan besar jika dibandingkan menggunakan monitor komputer biasa. Penerapan aplikasi berbasis web dimaksudkan agar program dapat di kendalikan melalui PC Client secara online, dimana saja, dan kapan saja oleh admin, sehingga hal ini akan menjadikan digital signage lebih efektif dan efisien dari segi waktu, tenaga, dan biaya serta mudah dalam hal pengoperasiannya.

Dengan adanya penelitian dan pembuatan desain Digital signage ini diharapkan dapat mengurangi dampak dari penggunaan papan pengumuman konvensional karena Digital Signage merupakan salah satu teknologi yang bisa digunakan untuk memberikan layanan informasi yang mudah, informatif, modern dan lebih efisien dalam segi waktu, tenaga dan biaya.

\section{METODE PENELITIAN}

\subsection{Metode Pengumpulan Data}

a. Observasi

Peneliti melakukan pengamatan terhadap perangkat papan informasi yang sudah ada untuk membandingkan kelemahan dan kelebihan masing-masing agar sistem yang dibuat oleh peneliti lebih baik dari papan informasi yang sudah ada.

b. Wawancara

Peneliti melakukan wawancara dengan pihak kampus STMIK AUB untuk mendapatkan masukan mengenai data apa saja yang akan di proses pada papan informasi. Berikutnya wawancara kepada sumber yang memiliki kompetensi tentang bagaimana merancang dan membuat rangkaian elektronik sebagai dasar pembuatan Digital Signage.

c. Studi Pustaka

Peneliti mencari dan mengumpulkan buku tentang perangkat ektronik Digital Signage, laporan penelitian terdahulu serta berbagai jurnal tentang perangkat elektronik terutama tentang perangkat elektronik berbentuk papan informasi baik nasional maupun internasional.

\subsection{Metode Pengembangan Sistem}

Prosedur pengembangan yang digunakan pada aplikasi ini adalah menggunakan prosedur pengembangan model Waterfall. Model ini melakukan pendekatan secara sistematis dan urut mulai dari level kebutuhan sistem lalu menuju ke tahap analisis, desain, coding, testing /verification, dan maintenance. Secara umum tahapan pada model waterfall dapat dilihat pada Gambar 1 berikut.

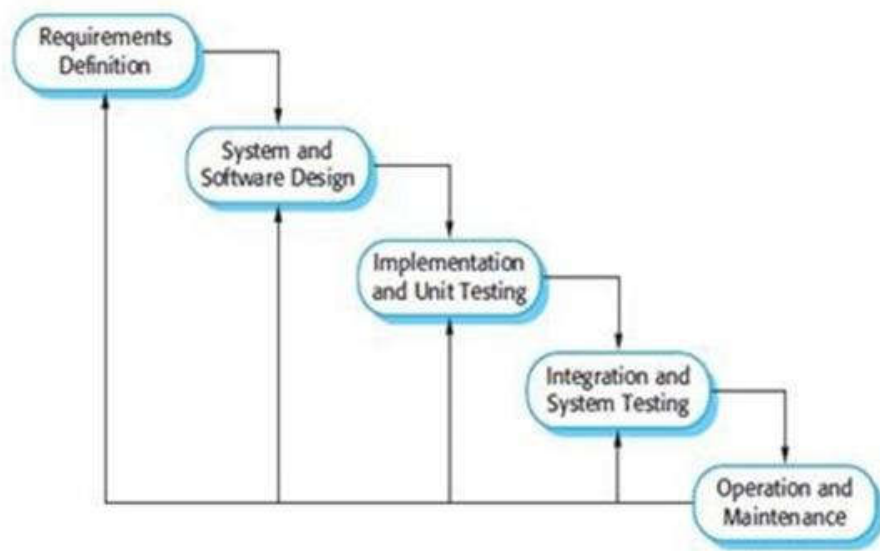

Gambar 1. Siklus Pengembangan Sistem dengan Model Waterfall

\subsection{Flowchart Sistem}

Flowchart sistem pada penelitian dapat dilihat pada Gambar 2 berikut. 


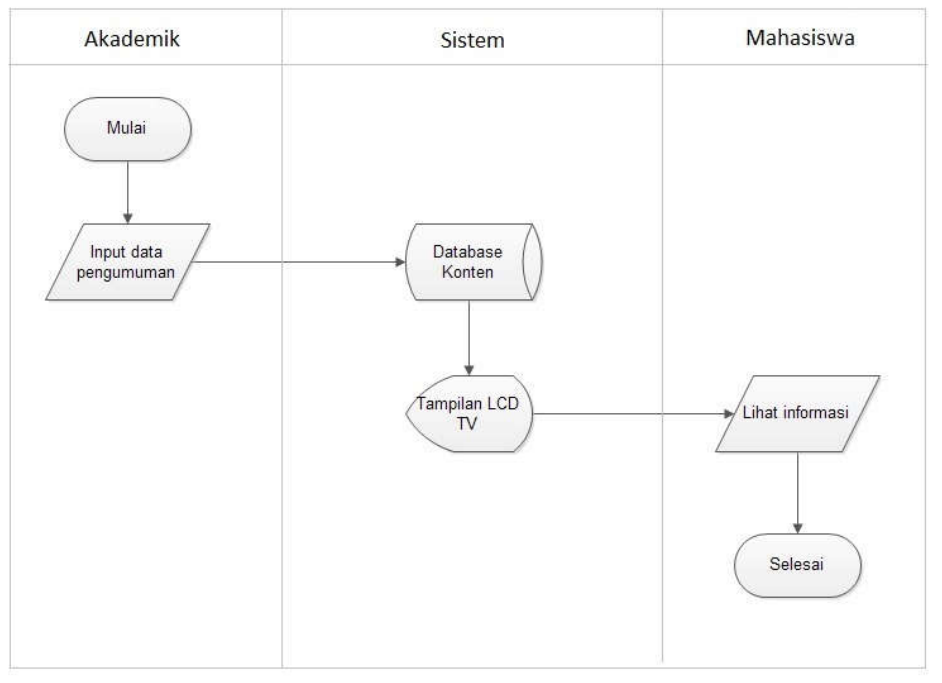

Gambar 2. Flowchart sistem

\subsection{Diagram Use case}

Usecase diagram mendiskripsikan sebuah interaksi antar satu atau lebih aktor dengan sistem yang akan dibuat. Usecase diagram mendefinisikan fitur dari sistem atau apa yang bisa dilakukan oleh sistem. Berikut Gambar 3 usecase Diagram Pengembangan Digital Signage sebagai Papan Informasi Digital.

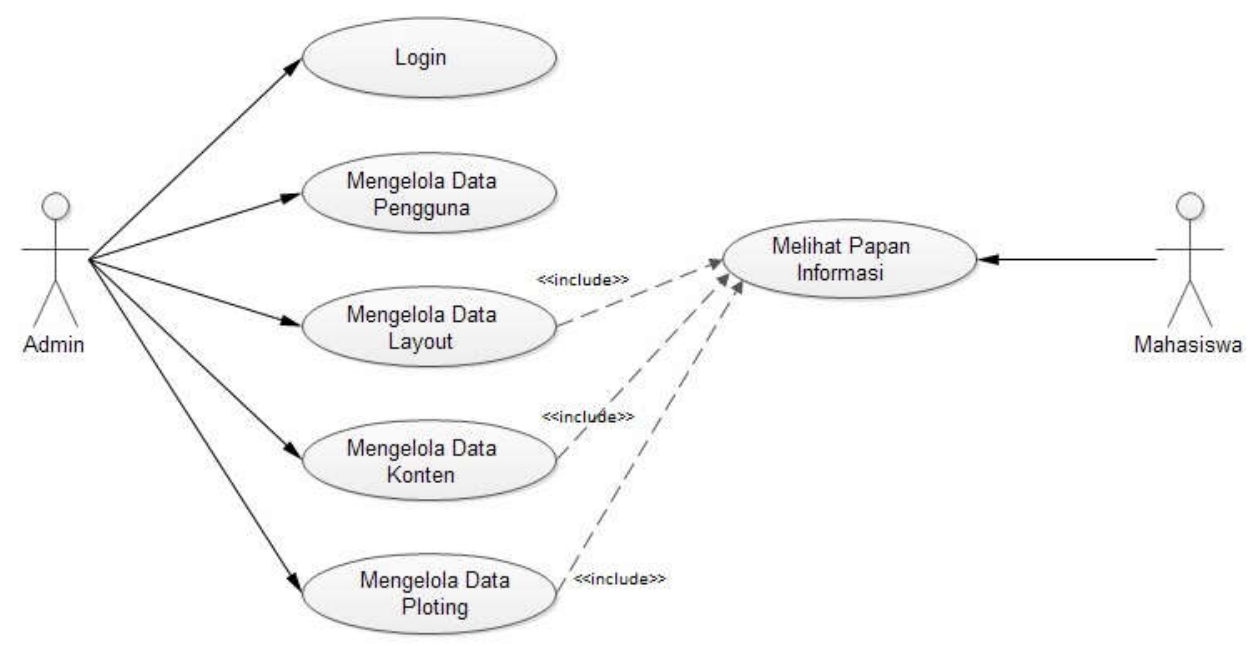

Gambar 2. Diagram Use Case

Gambar 2 adapun aktor - aktor yang terlibat dalam sistem dapat dilihat pada Tabel 1 sebagai berikut.

Tabel 1. Aktor yang terlibat didalam sistem

\begin{tabular}{|l|l|l|l|}
\hline No & Term & Synonym & Description \\
\hline 1 & $\begin{array}{l}\text { Staff Bagian } \\
\text { Administrasi } \\
\text { Umum }\end{array}$ & Admin & $\begin{array}{l}\text { Pihak yang berhak mengelola segala } \\
\text { informasi yang akan ditampilkan pada } \\
\text { papan informasi digital }\end{array}$ \\
\hline 2 & Mahasiswa & & $\begin{array}{l}\text { Pihak yang melihat hasil output sistem } \\
\text { berupa papan informasi digital }\end{array}$ \\
\hline
\end{tabular}

Usecase Narative adalah suatu fungsi untuk menjelaskan lebih detail mengenai elemen-elemen yang ada di dalam Use Case Diagram detail penjelasan dapat dilihat pada Tabel 2 berikut. 
Tabel 2 Usecase admin melakukan login

\begin{tabular}{|l|l|}
\hline Nama Usecase & Login \\
\hline Prioritas & Tinggi \\
\hline Tipe Usecase & Keamanan Sistem \\
\hline Pelaku & Admin \\
\hline Deskripsi & $\begin{array}{l}\text { Usecase ini mendeskripsikan tentang login sistem yang di mana } \\
\text { pengguna sistem di wajibkan mengsisi username dan password }\end{array}$ \\
\hline
\end{tabular}

Tabel 3. Usecase Admin mengelola data pengguna

\begin{tabular}{|l|l|}
\hline Nama Usecase & Mengelola Data Pengguna \\
\hline Prioritas & Tinggi \\
\hline Tipe Usecase & Keamanan Sistem \\
\hline Pelaku & Admin \\
\hline Deskripsi & $\begin{array}{l}\text { Usecase ini mendeskripsikan tentang mengelola data pengguna } \\
\text { meliputi nama, jabatan, username dan password yang digunakan } \\
\text { untuk masuk ke halaman administrator sistem. }\end{array}$ \\
\hline
\end{tabular}

Tabel 4. Usecase Admin mengelola data layout

\begin{tabular}{|l|l|}
\hline Nama Usecase & Mengelola Data Layout \\
\hline Prioritas & Tinggi \\
\hline Tipe Usecase & Keamanan Sistem \\
\hline Pelaku & Admin \\
\hline Deskripsi & $\begin{array}{l}\text { Usecase ini mendeskripsikan tentang mengelola data layout yang } \\
\text { digunakan sebagai tampilan tata letak papan informasi }\end{array}$ \\
\hline
\end{tabular}

Tabel 5. Usecase Admin mengelola data konten

\begin{tabular}{|l|l|}
\hline Nama Usecase & Mengelola Data Konten \\
\hline Prioritas & Tinggi \\
\hline Tipe Usecase & Keamanan Sistem \\
\hline Pelaku & Admin \\
\hline Deskripsi & $\begin{array}{l}\text { Usecase ini mendeskripsikan tentang mengelola data konten yang } \\
\text { meliputi data gambar, data video, dan data text }\end{array}$ \\
\hline
\end{tabular}

Tabel 6. Usecase Admin mengelola data ploting

\begin{tabular}{|l|l|}
\hline Nama Usecase & Mengelola Data Ploting \\
\hline Prioritas & Tinggi \\
\hline Tipe Usecase & Keamanan Sistem \\
\hline Pelaku & Admin \\
\hline Deskripsi & $\begin{array}{l}\text { Usecase ini mendeskripsikan tentang mengelola data ploting yang } \\
\text { meliputi data konten, kolom, waktu mulai dan waktu selesai konten } \\
\text { ditampilkan. }\end{array}$ \\
\hline
\end{tabular}

\subsection{Activity Diagram}

Activity Diagram menggambarkan aluran proses yang tedapat dalam mulai aktivitas start sampai aktivitas berhenti. Activity Diagram mendeskripsikan aksi-aksi dan hasilnya. Berikut ini adalah Activity diagram pada Gambar 3 sebagai berikut. 


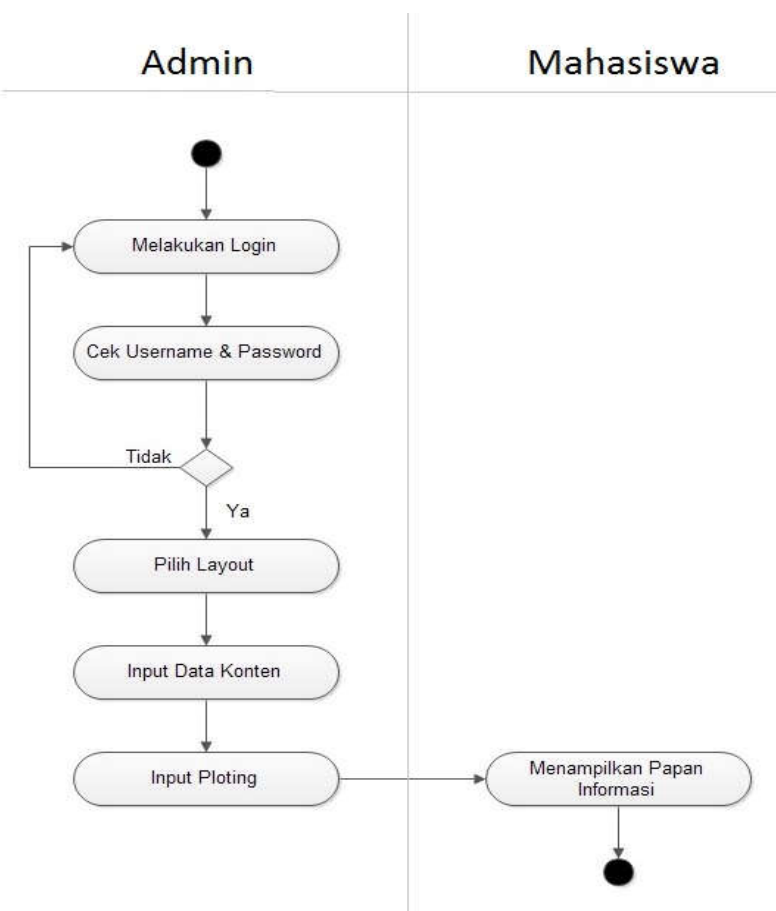

Gambar 3. Activity Diagram

Gambar 3 activity diagram pada aplikasi Digital Signage sebagai Papan Informasi Digital, admin melakukan login sesuai username dan password yang sudah dimiliki, jika username password benar maka langsung menuju halaman pilih layout, setelah itu input data konten lalu input ploting. Setelah selesai maka mahasiswa dapat melihat papan informasi pada layar LCD.

\subsection{Metode PIECES}

Untuk menganalisa perbandingan sistem diperlukan langkah untuk mengidentifikasi sistem yang ada, maka sebagai landasan penulis menggunakan metode atau kerangka PIECES yang terdiri dari performance, information, economy, control, efficiency dan service. Metode PIECES dapat dilihat pada Tabel 7 berikut.

Tabel 7. Pembahasan Sistem

\begin{tabular}{|l|l|}
\hline \multicolumn{1}{|c|}{ Analisa } & \multicolumn{1}{|c|}{ Sistem Baru } \\
\hline $\begin{array}{l}\text { Performance } \\
\text { (Kinerja) }\end{array}$ & $\begin{array}{l}\text { Dengan adanya sistem baru semua bentuk informasi dan } \\
\text { pengumuman tersimpan di database yang bisa ditampilkan } \\
\text { kapan saja secara real time }\end{array}$ \\
\hline Informasi (Informasi) & $\begin{array}{l}\text { Proses penyampaian informasi yang disajikan dalam } \\
\text { berbagai macam konten lebih mudah dipahami secara detail } \\
\text { dan menyeluruh }\end{array}$ \\
\hline Economy (Ekonomi) & $\begin{array}{l}\text { Tidak perlu menggunakan kertas dan dapat menyampaikan } \\
\text { banyak informasi sekaligus dengan sumber daya yang sama }\end{array}$ \\
\hline Control (Keamanan) & $\begin{array}{l}\text { Keamanan data terjamin, karena untuk mengakses aplikasi } \\
\text { harus melalui login pengguna, serta jika ada perubahan data } \\
\text { konten akan tercatat waktu dan pengguna yang melakukan } \\
\text { perubahan data konten }\end{array}$ \\
\hline Efficiency (Efisiensi) & $\begin{array}{l}\text { Waktu yang diperlukan sedikit karena setelah informasi } \\
\text { dientri saat itu juga informasi bisa disebarkan }\end{array}$ \\
\hline Service (Layanan) & $\begin{array}{l}\text { Informasi yang disampaikan bervariatif mulai dari text, } \\
\text { gambar dan video, serta dapat diatur dari mana saja secara } \\
\text { online }\end{array}$ \\
\hline
\end{tabular}




\section{HASIL DAN PEMBAHASAN}

\subsection{Hasil Pengujian}

Data hasil pengujian fitur diperoleh dari kemampuan Digital Signage yang terhubung dengan server menampilkan fitur-fitur yang dimiliki, seperti menampilkan informasi berbasis teks statis, teks dinamis, gambar statis, gambar dinamis, dan video secara sempurna pada PC client yang terhubung dengan display monitor. Hasil pengujian dapat dilihat pada Tabel 8 berikut.

Tabel 8. Hasil Pengujian

\begin{tabular}{|l|l|}
\hline \multicolumn{1}{|c|}{ Display } & \multicolumn{1}{c|}{ Keterangan } \\
\hline Teks Statis & Mampu menampilkan teks statis secara sempurna. \\
\hline Teks Dinamis & $\begin{array}{l}\text { Hanya mampu menampilkan teks dinamis yang bergerak } \\
\text { horizontal dan vertical (marquee). }\end{array}$ \\
\hline Image Statis & $\begin{array}{l}\text { Mampu secara sempurna menampilkan image statis yang } \\
\text { berformat jpg, jpeg, png, dan bmp. }\end{array}$ \\
\hline Image Dinamis & $\begin{array}{l}\text { Mampu secara sempurna menampilkan image dinamis yang } \\
\text { berformat gif. }\end{array}$ \\
\hline Video & Mampu menampilkan video dengan format mp4 dan avi. \\
\hline
\end{tabular}

\subsection{Pembahasan}

Berikut ini halaman login aplikasi Digital Signage dengan menggunakan akun yang sudah terdaftar.

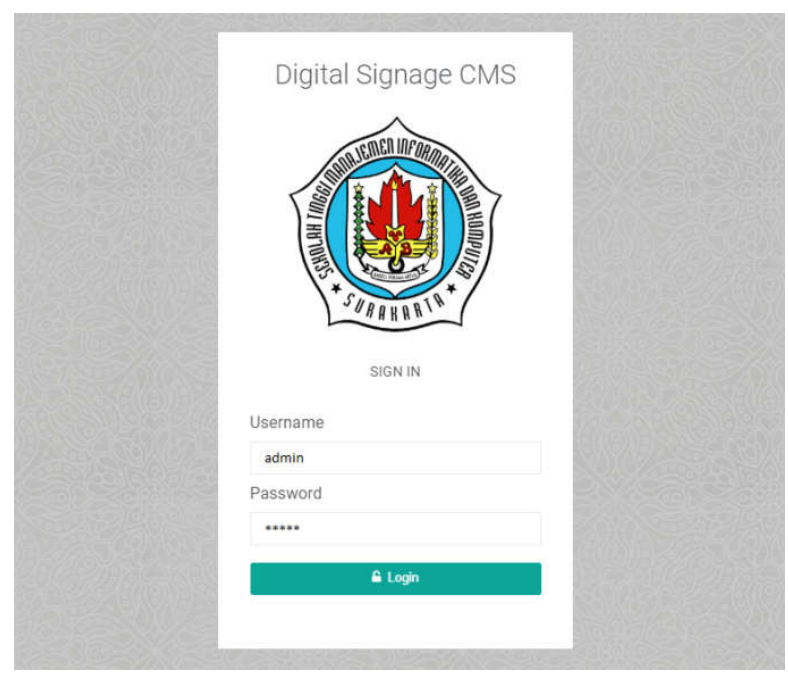

Gambar 4. Halaman login aplikasi

Gambar 4 untuk menuju halaman login dapat dilakukan dengan masuk ke url http://infostmikaub.online lalu akan muncul halaman administrator dan mengisi username dan password yang sudah terdaftar lalu klik tombol Login.

Pada menu konten terdapat tiga tombol untuk menambahkan konten yang berbeda yaitu Entri Image, Entri Video, dan Entri Text. Tampilan awal yang muncul dapat dilihat pada Gambar 5 berikut. 


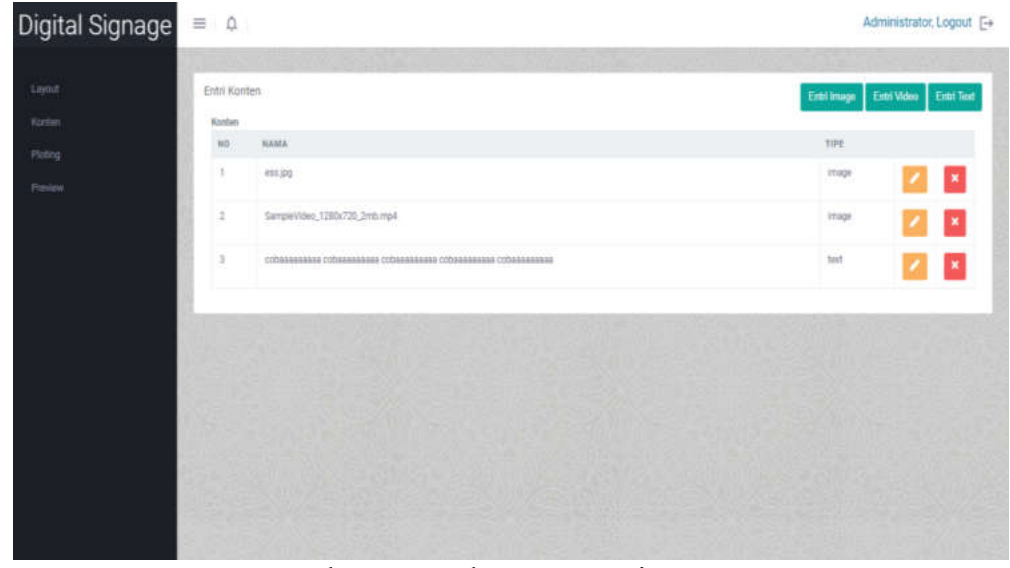

Gambar 5. Halaman Entri Konten

Gambar 5 untuk menambahkan konten berupa gambar klik tombol Entri Image, untuk menambahkan konten berupa video klik tombol Entri Video, untuk menambahkan konten berupa text klik tombol Entri Text, setelah tombol entri diklik maka akan muncul modal Gambar 6 berikut.

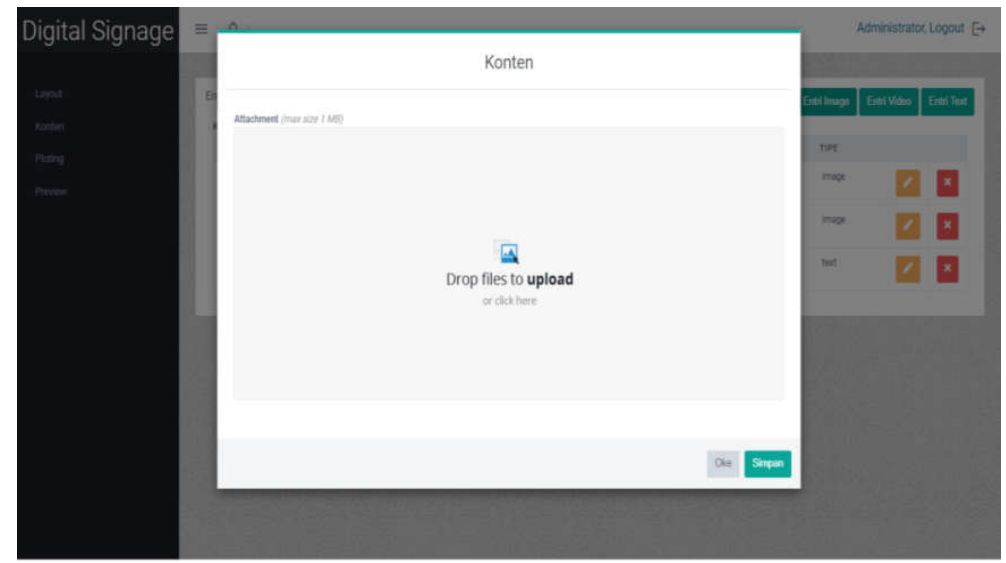

Gambar 6. Modal Entri Konten

Pada menu pengaturan layout akan muncul tiga layout yang berbeda, masing-masing memiliki jumlah kolom yang berbeda yaitu satu kolom, dua kolom, dan tiga kolom. Untuk memilih layout yang akan digunakan klik layout seperti Gambar 7 layout lalu klik tombol Simpan.

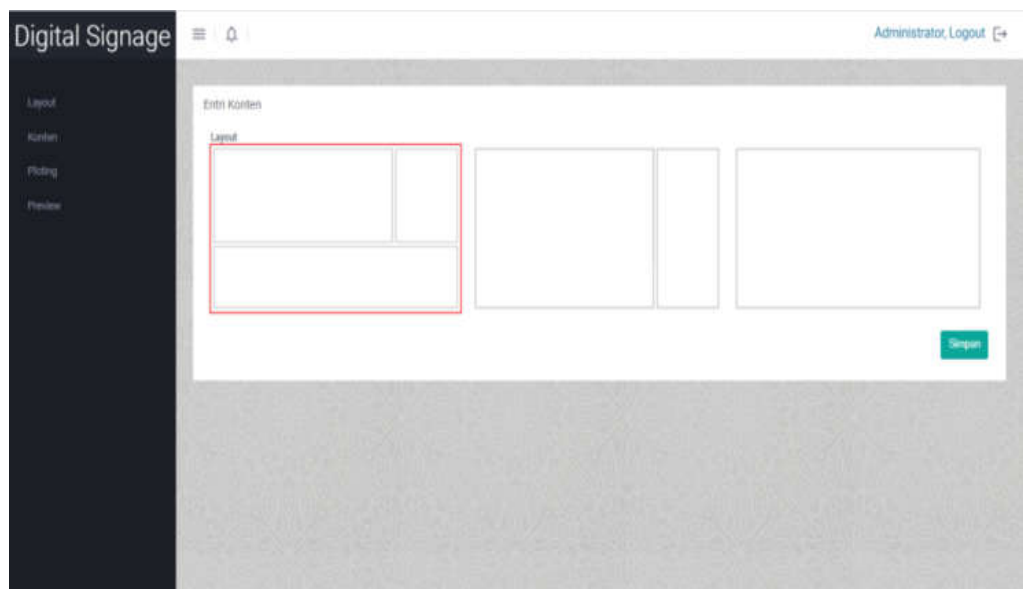

Gambar 7. Halaman Layout Konten 
Berikutnya Gambar 8 halaman pengaturan konten digunakan untuk menambah, mengubah, dan menghapus konten berupa gambar, video, text dan google slides. Untuk menambahkan konten dilakukan dengan cara klik tombol Entri Image, Entri Video, atau Entri Text. Selanjutnya isi konten sesuai kebutuhan lalu klik tombol Simpan

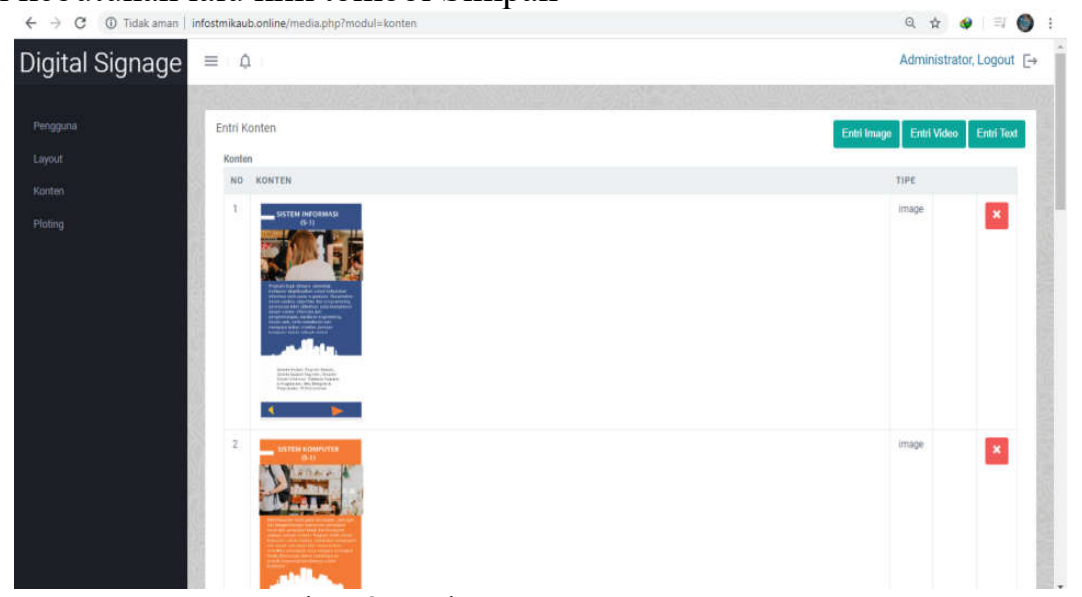

Gambar 8. Halaman Pengaturan Konten.

Berikutnya pada halaman ploting Gambar 9 menampilkan form isian berupa konten, kolom, mulai, dan sampai. Ploting digunakan untuk menempatkan konten pada kolom tertentu berdasarkan layout yang telah dipilih. Untuk menempatkan konten pada layout, pilih konten, lalu pilih kolom, lalu isi jam mulai dan jam selesai, setelah itu klik tombol Simpan.

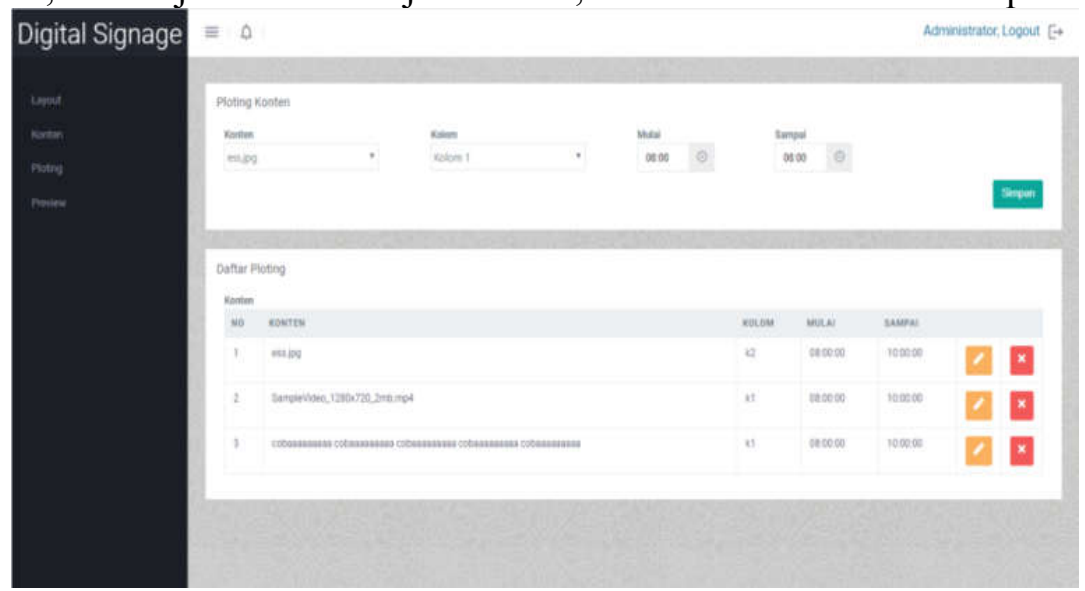

Gambar 9. Halaman Ploting Konten

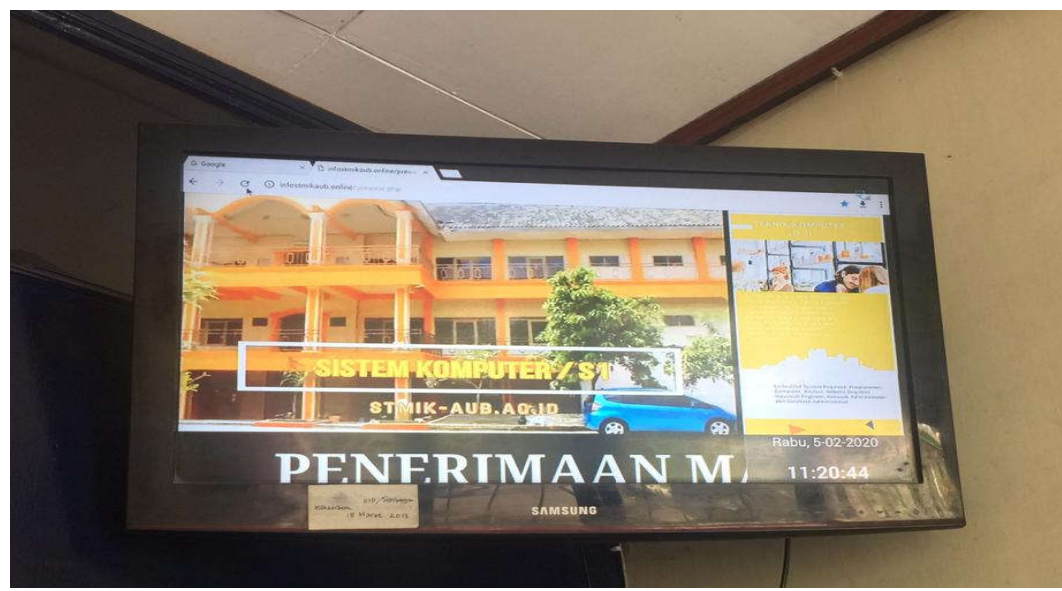

Gambar 10. Display Digital Signage pada LED TV 
Gambar 10 menampilkan LED TV yang sudah terhubung dengan STB dan jaringan internet mengakses alamat address server dan menampilkan papan informasi digital sesuai dengan format layout yang telah diatur pada Gambar 7.

\section{KESIMPULAN}

Berdasarkan dari hasil perancangan dan pengujian alat, maka dapat ditarik kesimpulan sebagai berikut. Penelitian ini telah berhasil merancang dan membangun papan informasi digital sebagai alat penyampaian informasi di STMIK AUB Surakarta menggunakan bahasa pemrograman PHP, HTML, CSS dan Javascript dengan database MySQL. Aplikasi Digital Signage dapat menyampaikan informasi secara dinamis dan atraktif tidak monoton seperti text, gambar dan video serta dapat menyampaikan informasi secara real time.

\section{SARAN}

Papan informasi digital yang dibuat masih jauh dari kesempurnaan maka dari itu diperlukan pengembangan lebih lanjut diantaranya saat ini layout terbatas pada tiga tampilan saja berikutnya diharapkan dapat menambahkan layout yang lebih dinamis. Selanjutnya pada pengaturan waktu tayang dapat ditambahkan pengaturan per tanggal, bulan dan tahun sehingga dapat disesuaikan perubahan konten dengan waktu tayang.

\section{DAFTAR PUSTAKA}

[1] Suranata, Wardana. 2014. Digital Signage sebagai Media Penyampaian Informasi Kegiatan Akademik Berbasis Mikrokomputer. Bali: Creative Information Technology Journal.

[2] Mulyana, Aria, 2016, Perancangan Digital Signage Sebagai Papan Informasi Digital, Program Studi Sistem Komputer, Fakultas Teknik dan Ilmu Komputer Universitas Komputer Indonesia.

[3] Nugroho. 2004. PHP dan MySQL dengan editor Dreamweaver MX. CV Andi Offset. Yogyakarta

[4] Jogiyanto. 2008. Metodologi Penelitian Sistem Informasi. CV Andi Offset. Yogyakarta

[5] Wahana. 2010. Panduan Belajar MySQL Database Server. Jakarta: Mediakita. Mukhamad, Masrur 2016. Pemrograman Web Dinamis menggunakan Java Server Pages dengan Database Relasional MYSQL. CV Andi Offset. Yogyakarta

[6] Riyanto. 2014. Kupas Tuntas WEB Responsif. Jakarta: PT. Alex Komputindo.

[7] Rizal Panuntun, Adian Fatchur Rochim, Kurniawan Teguh Martono, 2012, Perancangan Papan Informasi Digital Berbasis Web pada Raspberry pi, Jurusan Sistem Komputer Fakultas Teknik Universitas Diponegoro.

[8] Yuhefizar, Mooduto. 2009. Cara Mudah Membangun Website Interaktif Menggunakan Content Management System Joomla (CMS). Jakarta: PT Elex Media Komputindo 